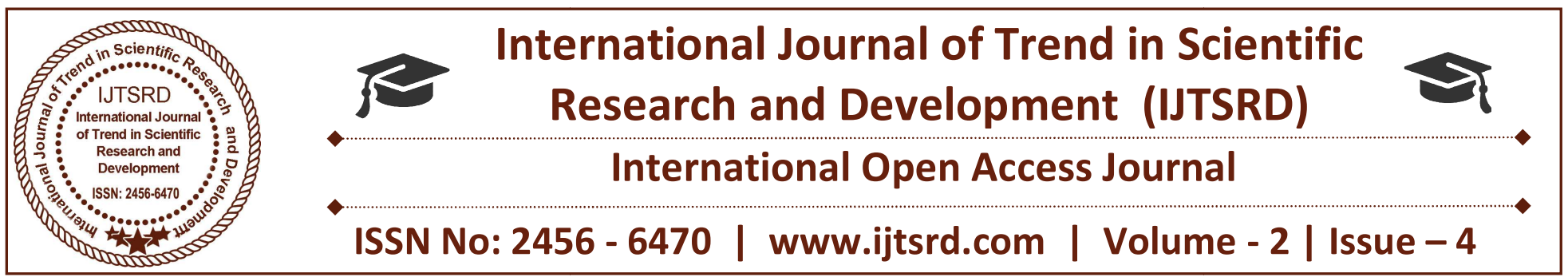

\title{
Analysis of Power Transfer Capability of a Long Transmission Line Using FACTS Devices
}

\author{
K. Suneel Goutham, M. Bhaskar Rao, T. Jaganmohan Rao \\ Assistant Professor, Aditya nstitute of Technology and Management, \\ Tekkali, Andhra Pradesh, India
}

\begin{abstract}
This paper gives insight for the improvement of power transfer capability by analyzing and comparing several FACTS devices such as Static Var Compensator (SVC), Static Synchronous Compensator (STATCOM) and Unified Power Flow Controller (UPFC) in long transmission line. These devices have been used in different locations such as sending end, middle and receiving end of transmission line. The suitable location and performance of each model has been analyzed. Firstly, real and reactive power profiles have been studied for uncompensated system and subsequent results are produced. Then these results are compared with the results obtained after compensating the system using afore mentioned FACTS devices. Overall analysis indicates that better power (i.e. $87.24 \%$ power) has been transferred when $\mathrm{SVC}$ is connected at the middle of the transmission line. All simulations have been done in MATLAB/SIMULINK.
\end{abstract}

Keywords: FACTS, power profile, real and reactive power, STATCOM, SVC, UPFC, Voltage magnitude

\section{INTRODUCTION}

${ }^{1}$ Power transmission is the movement of energy from generating end to the loading end. But now-a-days increasing of generation cost and transmission loss are the major problems. Development of power electronics based devices help to improve transmission loss and increase the power transfer capability of power system. Parameters like voltage, real and reactive power flow can be controlled by using FACTS devices in transmission line. In this paper Static Synchronous Compensator (STATCOM), Static VAR Compensator (SVC) and Unified Power Flow Controller (UPFC) have been used to verify the performance and determine the power transfer quality. UPFC model is incorporated in a single and double transmission system (6.6/22) KV for real time control and dynamic compensation of $\mathrm{AC}$ transmission system. It improves voltage and power profiles in the UPFC compensated system [1]. By using FACTS devices in long transmission line power transfer capability has been improved a lot and it has also controlled the power flow in the power network where power transfer capability has been calculated and power flow is compared by using FACTS devices in different locations of long transmission line [2]. The construction and the working principle of various FACTS devices have been discussed with the description of power circuit, associated controllers and operating mode [3]. The improvements of power flow and voltage profile with the use of fixed capacitor, STATCOM and SVC have been investigated. Voltage instability in power system occurs when the system is unable to meet the reactive power demand as per system requirements [4]. Operation of power system should be economical. Load frequency control and reactive power control are two major aspects for better operation of any power systems [5]. UPFC simulation has been studied in the UPFC connected 3-phase system. This paper showed that the real and reactive power increased with increment in the angle of injection [6]. Enhancement of power system stability and improvement of power transfer capability have been shown by using various FACTS devices in the system. After doing all the simulation, results have been verified and comparison of power profiles with uncompensated and FACTS compensated system is demonstrated [7]. FACTS controller such as SVC and Thyristor Control Voltage 
Regulator are used at the load end to maintain the voltage profile by using SVC in parallel with the load where TCVR gives the series injection [8]. It is shown by M.Kowsalya et al. that the location where the FACTS devices are used to get higher benefits and control of reactive power [9]. D. Murali et al. demonstrated that active and reactive power flow control and improvement of transient stability can be done by using UPFC in both series and shunt parameters. The simulation results demonstrate the effectiveness and robustness of the proposed UPFC on transient stability improvement of the system [10]. Improvement of power system performance with VAR compensation have been shown here. Reactive power control has been observed by shunt and series capacitive arrangement [11]. Voltage dynamics and oscillations can be controlled by using shunt connected FACTS devices. Power transfer capability, stability and reliability of transmission systems could be further increased by using the inventive strategies incorporating system-wide control logic. Controllers would be able to maximize available transfer capacity which maintains dynamic stability and security [12]. Improvement of power transfer capacity, quality and reliability by using UPFC [13] and a comparative study of the performances with other FACTS devices have been demonstrated.

\section{CIRCUIT DESCRIPTION}

The power grids consist of two equivalent sources of $500 \mathrm{KV}$ 3000MVAR each, connected with $700 \mathrm{~km}$ long transmission line. Three loads of $150 \mathrm{MW}$ each are connected. 1756.3 MW power has been transferred from bus B1 to B3. When the FACTS devices were not connected, the percentage of power flow capability was $79.72 \%$. The circuit diagram of uncompensated system is given below:

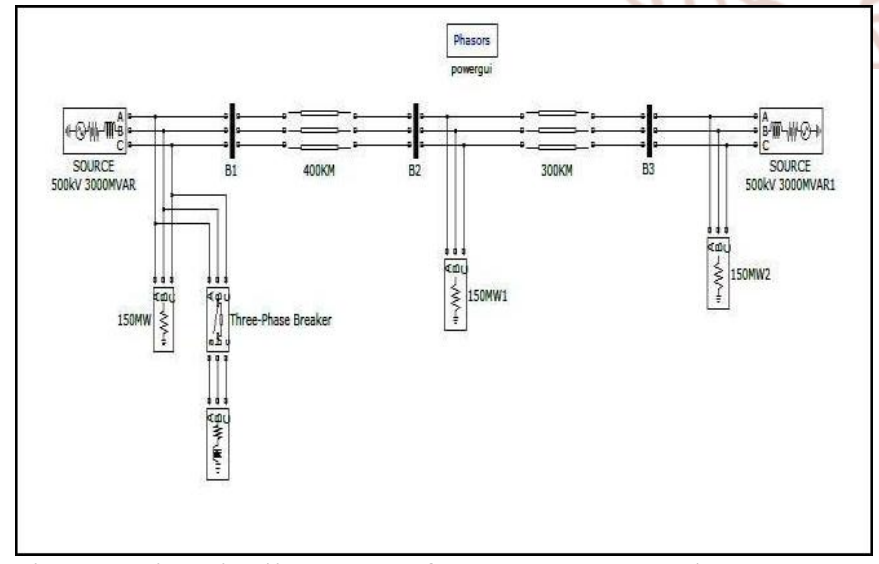

Fig. 1. Circuit diagram of uncompensated system

The shunt FACTS device STATCOM has been added to the circuit which has rating of +/- $100 \mathrm{MVA}$. Also it has DC link nominal voltage of $40 \mathrm{KV}$ with an equivalent capacitance $375 \mu \mathrm{F}$. The simulation results have been collected by changing the location of STATCOM i.e. sending end, middle and receiving end of the transmission line. Also the simulation results have been collected by changing the location of SVC and UPFC.

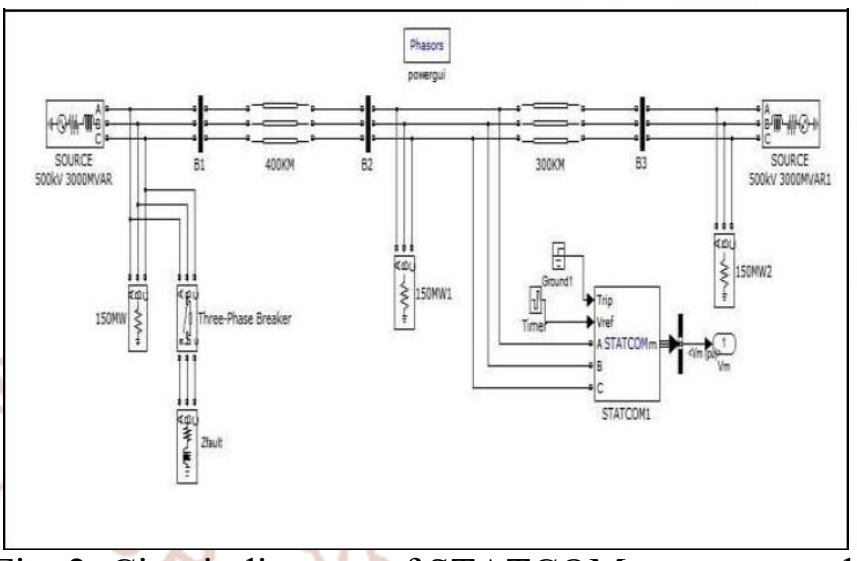

Fig. 2. Circuit diagram of STATCOM compensated system

\section{SIMULATION RESULTS AND DISCUSSION}

The real and reactive power flows of uncompensated system are tabulated bellow:

Scientific TABLE 1
\begin{tabular}{|c|c|c|c|}
\hline Power Flow & B1 & B2 & B3 \\
\hline P(MW) & 1756.3 & 1728.0 & 1400.1 \\
\hline Q(MVAR) & 1292.7 & 1259.9 & 1129.6 \\
\hline
\end{tabular}

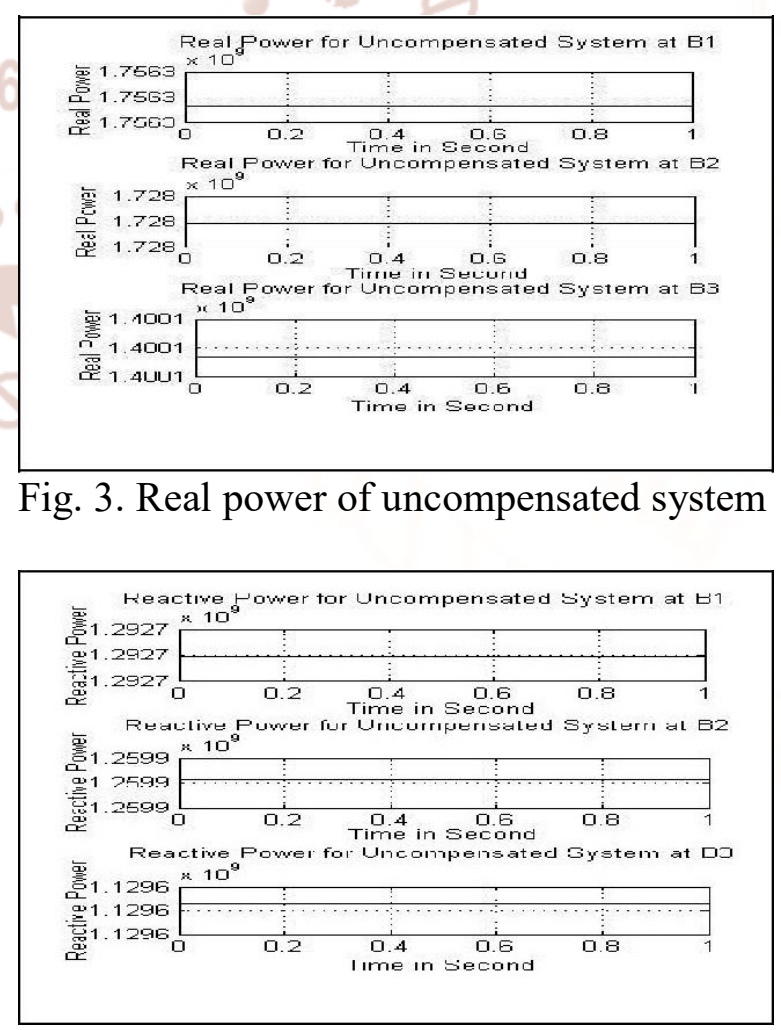

Fig.4. Reactive power of uncompensated system 
The above graphs (Fig 3 and Fig 4) show the real and reactive power flow of uncompensated system. It is seen that $79.72 \%$ power has been transferred from bus B1 to bus B3.

The real and reactive power flows of STATCOM compensated system are tabulated bellow:

TABLE 2

\begin{tabular}{|l|l|l|l|l|}
\hline Position & $\begin{array}{l}\text { Power } \\
\text { Flow }\end{array}$ & B1 & B2 & B3 \\
\hline \multirow{2}{*}{$\begin{array}{l}\text { Sending } \\
\text { End }\end{array}$} & P(MW) & 1723.1 & 1707.7 & 1389.0 \\
\cline { 2 - 5 } Middle & Q(MVAR) & 1241.5 & 1187.3 & 1064.0 \\
\cline { 2 - 5 } & P(MW) & 1621.6 & 1609.0 & 1405.1 \\
\hline \multirow{2}{*}{$\begin{array}{l}\text { Receiving } \\
\text { End }\end{array}$} & P(MVAR) & 1351.9 & 1292.8 & 994.5 \\
\cline { 2 - 5 } & Q(MVAR) & 1682.2 & 1651.4 & 1346.1 \\
\hline
\end{tabular}

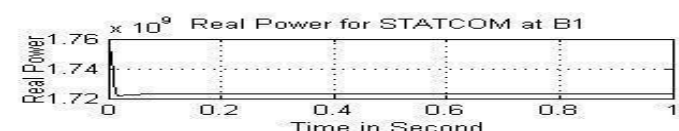

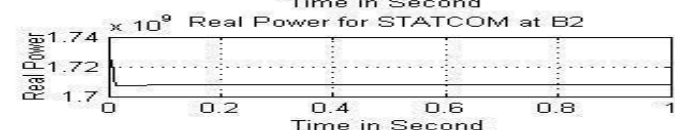

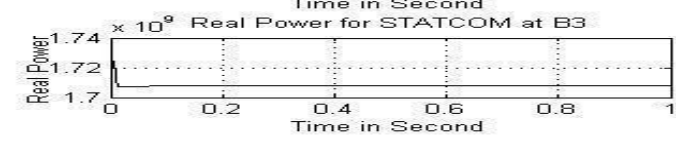

Fig. 5. Real power flow of STATCOM compensated system (Sending End)

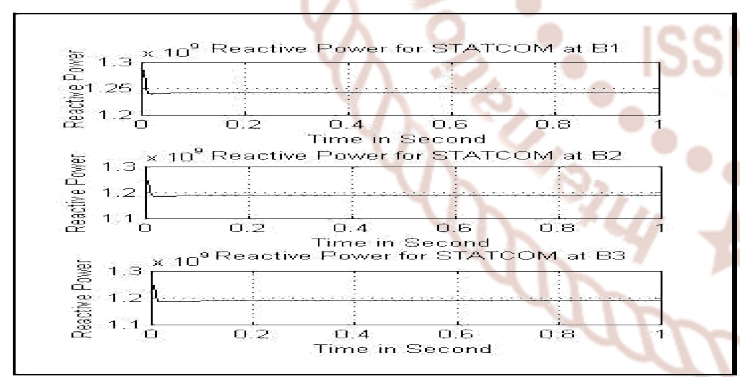

Fig. 6. Reactive power flow of STATCOM compensated system (Sending End)

The above graphs (Fig 5 and Fig 6) show the real and reactive power flow of STATCOM compensated system. It is seen that $80.61 \%$ power has been transferred from bus B1 to bus B3 when STATCOM is connected at sending end of transmission line.

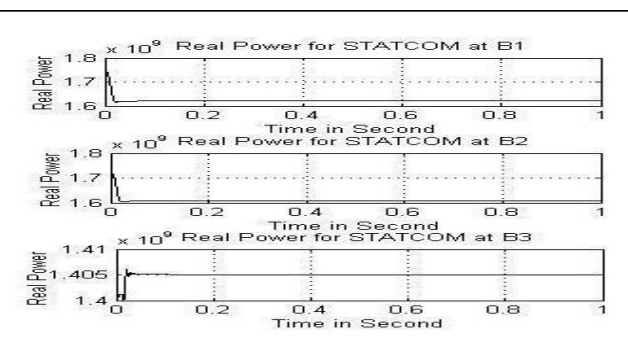

Fig. 7. Real power flow of STATCOM compensated system (Middle)

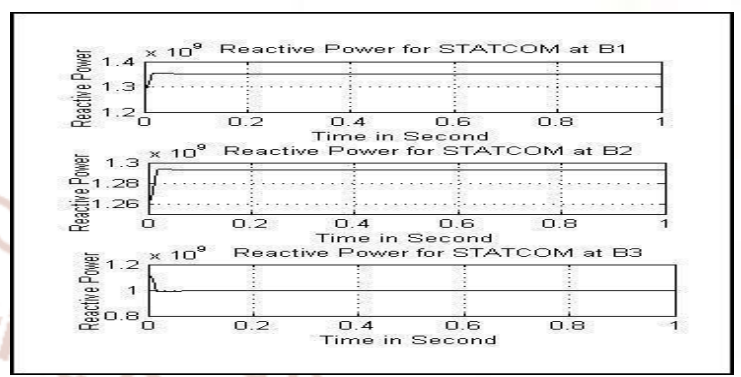

Fig. 8. Reactive power flow of STATCOM compensated system (Middle)

The above graphs (Fig 7 and Fig 8) show the real and reactive power flow of SATCOM compensated system. It is seen that $86.65 \%$ power has been transferred from bus B1 to bus B3 when STATCOM is connected at middle of transmission line.

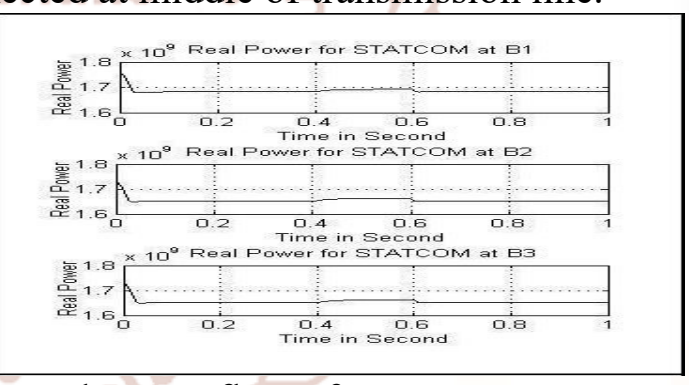

Fig. 9. Real power flow of STATCOM compensated system (Receiving End)

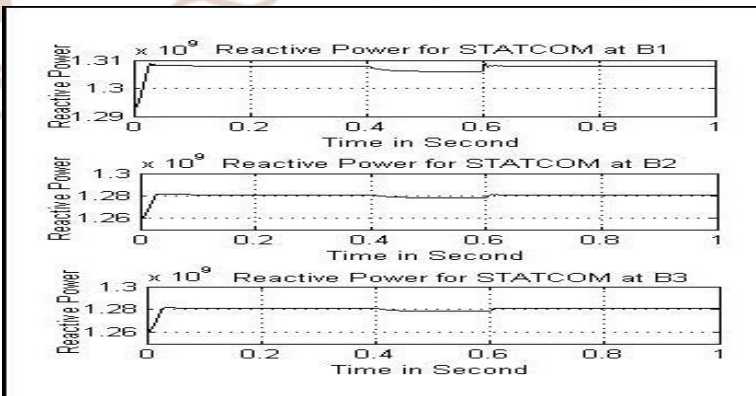

Fig. 10. Reactive power flow of STATCOM compensated system (Receiving End)

The above graphs (Fig 9 and Fig 10) show the real and reactive power flow of STATCOM compensated system. It is seen that $80.02 \%$ power has been transferred from bus B1 to bus B3 when STATCOM is connected at receiving end of transmission line. 
International Journal of Trend in Scientific Research and Development (IJTSRD) ISSN: 2456-6470

The real and reactive power flows of SVC compensated system are tabulated bellow:

TABLE 3

\begin{tabular}{|l|l|l|l|r|}
\hline Position & $\begin{array}{l}\text { Power } \\
\text { Flow }\end{array}$ & B1 & B2 & B3 \\
\hline \multirow{2}{*}{$\begin{array}{l}\text { Sending } \\
\text { End }\end{array}$} & P(MW) & 1717.6 & 1704.5 & 1387.4 \\
\cline { 2 - 5 } Middle & Q(MVAR) & 1233.5 & 1175.6 & 1053.2 \\
\cline { 2 - 5 } & P(MW) & 1611.5 & 1599.8 & 1405.9 \\
\hline \multirow{2}{*}{$\begin{array}{l}\text { Receiving } \\
\text { End }\end{array}$} & P(MW $)$ & 1355.6 & 1295.2 & 985.3 \\
\cline { 2 - 5 } & Q(MVAR) & 1308.1 & 1281.6 & 1133.1 \\
\hline
\end{tabular}

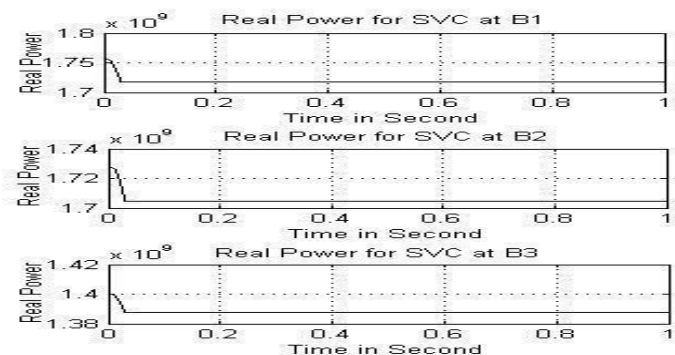

Fig. 11. Real power flow of SVC compensated system (Sending End)

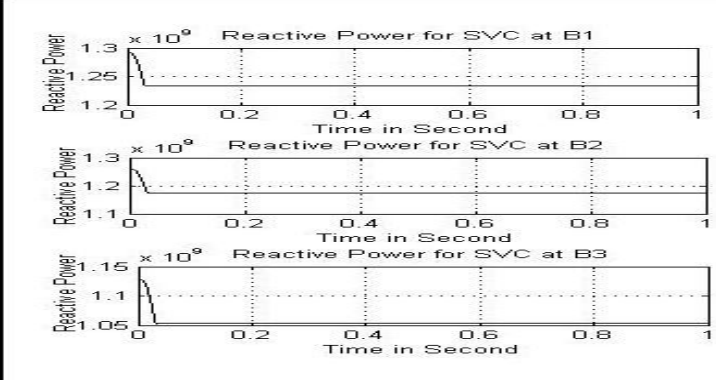

Fig. 12. Reactive power flow of SVC compensated system (Sending End)

The above graphs (Fig 11 and Fig 12) show the real and reactive power flow of SVC compensated system. It is seen that $80.78 \%$ power has been transferred from bus B1 to bus B3 when SVC is connected at sending end of transmission line.

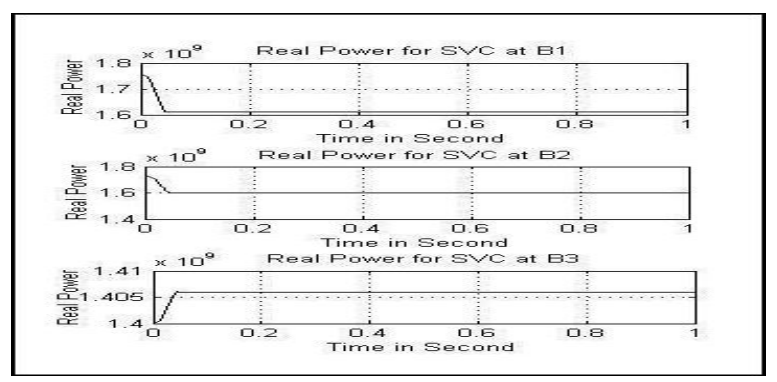

Fig. 13. Real power flow of SVC compensated system (Middle)

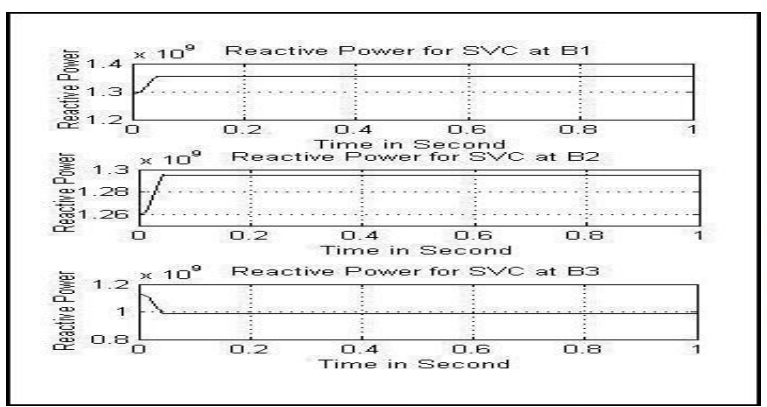

Fig. 14. Reactive power flow of SVC compensated system (Middle)

The above graphs (Fig 13 and Fig 14) show the real and reactive power flow with the change of simulation time at SVC compensated system. It is seen that $87.24 \%$ power has been transferred from bus B1 to bus B3 when SVC is connected at middle of transmission line.

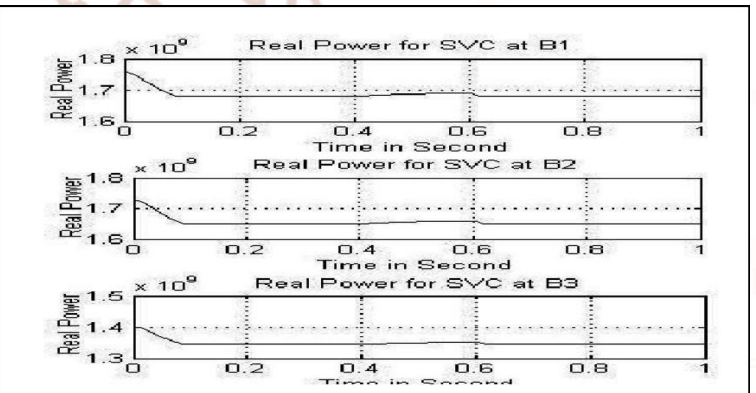

Fig. 15. Real power flow of SVC compensated system (Receiving End).

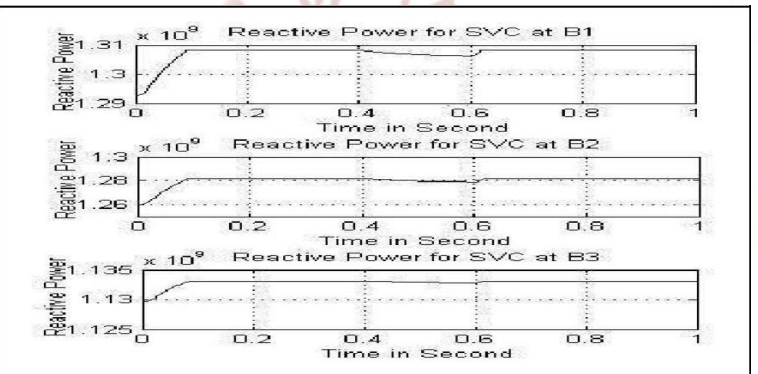

Fig. 16. Reactive power flow of SVC compensated system (Receiving End)

The above graphs (Fig 15 and Fig 16) show the real and reactive power flow of SVC compensated system. It is seen that $80.01 \%$ power has been transferred from bus B1 to bus B3 when SVC is connected at receiving end of transmission line.

The real and reactive power flows of SVC compensated system are tabulated bellow: 
TABLE 4

\begin{tabular}{|l|l|c|c|c|}
\hline Position & $\begin{array}{c}\text { Power } \\
\text { Flow }\end{array}$ & B1 & B2 & B3 \\
\hline $\begin{array}{l}\text { Sending } \\
\text { End }\end{array}$ & P(MW) & 1723.1 & 1707.6 & 1388.8 \\
\cline { 2 - 5 } Q(MVAR) & 1241.2 & 1187.1 & 1064.0 \\
\hline Middle & P(MW) & 1621.8 & 1609.5 & 1404.7 \\
\cline { 2 - 5 } & Q(MVAR) & 1352.2 & 1292.7 & 994.3 \\
\hline $\begin{array}{l}\text { Receiving } \\
\text { End }\end{array}$ & P(MW) & 1682.3 & 1651.8 & 1346.4 \\
\cline { 2 - 5 } Q(MVAR) & 1308.2 & 1281.0 & 1132.7 \\
\hline
\end{tabular}

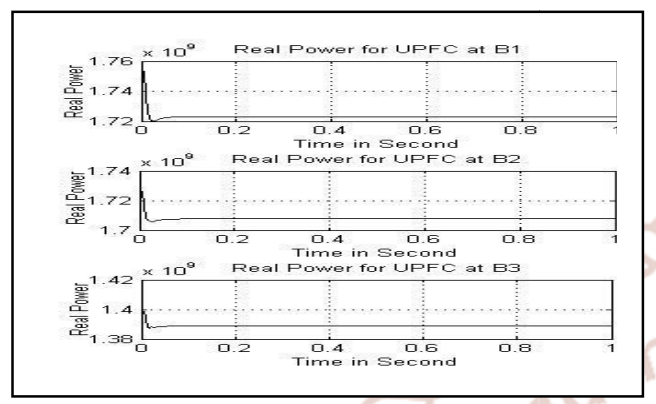

Fig. 17. Real power flow of UPFC compensated system (Sending End)

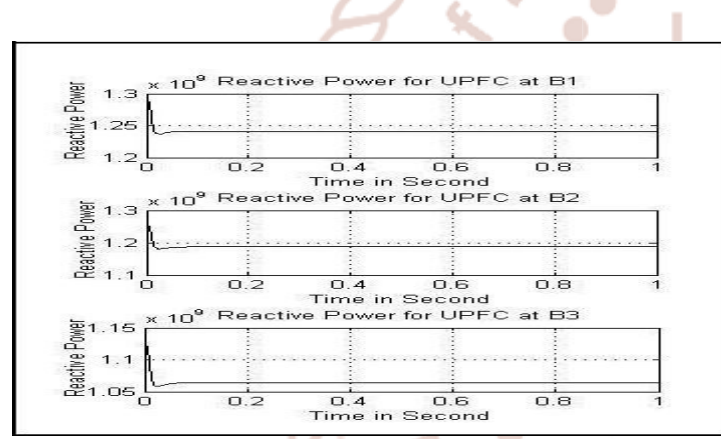

Fig. 18. Reactive power flow of UPFC compensated system (Sending End)

The above graphs (Fig 17 and Fig 18) show the real and reactive power flow of UPFC compensated system. It is seen that $80.60 \%$ power has been transferred from bus B1 to bus B3 when UPFC is connected at sending end of transmission line.

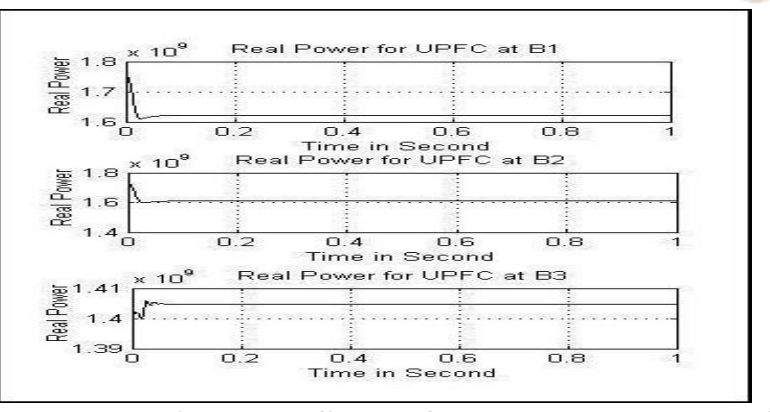

Fig. 19. Real power flow of UPFC compensated system (Middle)

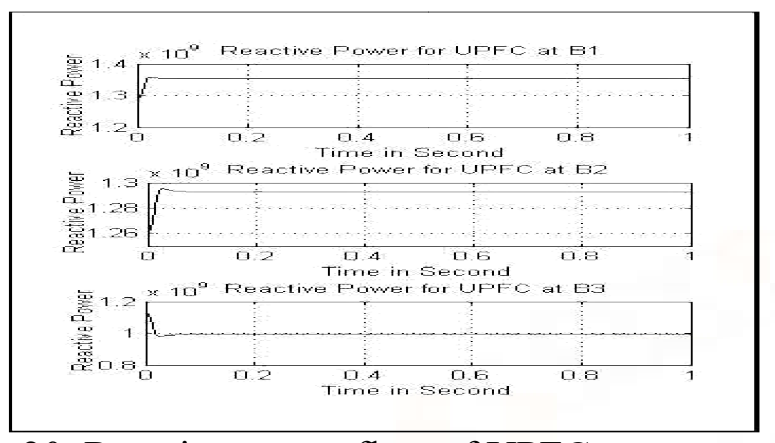

Fig. 20. Reactive power flow of UPFC compensated system (Middle)

The above graphs (Fig 19 and Fig 20) show the real and reactive power flow of UPFC compensated system. It is seen that $86.61 \%$ power has been transferred from bus B1 to bus B3 when UPFC is connected at middle of transmission line.

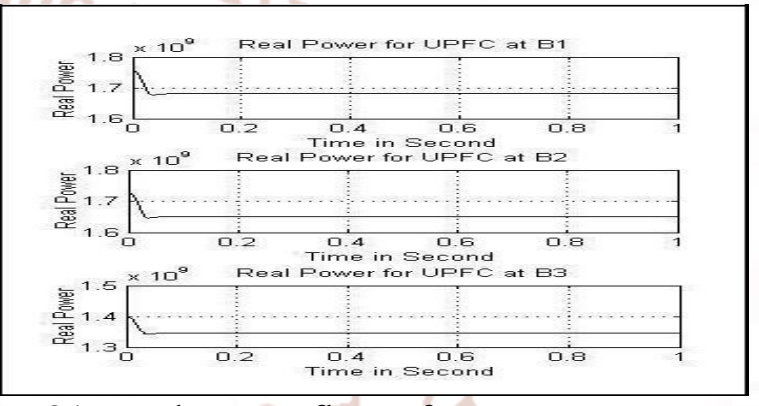

Fig. 21. Real power flow of UPFC compensated system (Receiving End)

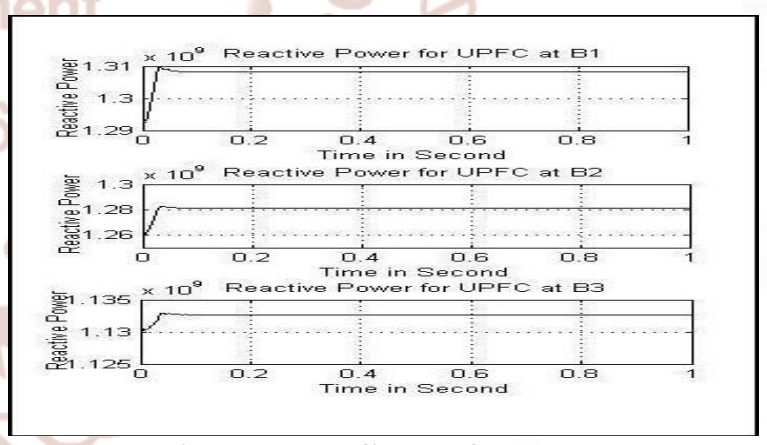

Fig. 22. Reactive power flow of UPFC compensated system (Receiving End)

The above graphs (Fig 21 and Fig 22) show the real and reactive power flow of UPFC compensated system. It is seen that $80.03 \%$ power has been transferred from bus B1 to bus B3 when UPFC is connected at receiving end of transmission line. 


\section{COMPARISON OF POWER TRANSFER CAPABILITY}

\section{TABLE 2}

\begin{tabular}{|c|c|c|c|}
\hline Position & STATCOM & SVC & UPFC \\
\hline $\begin{array}{c}\text { Sending } \\
\text { End }\end{array}$ & $80.61 \%$ & $80.78 \%$ & $80.60 \%$ \\
\hline $\begin{array}{c}\text { Sending } \\
\text { End }\end{array}$ & $86.65 \%$ & $87.24 \%$ & $86.61 \%$ \\
\hline $\begin{array}{c}\text { Receiving } \\
\text { End }\end{array}$ & $80.02 \%$ & $80.01 \%$ & $80.03 \%$ \\
\hline
\end{tabular}

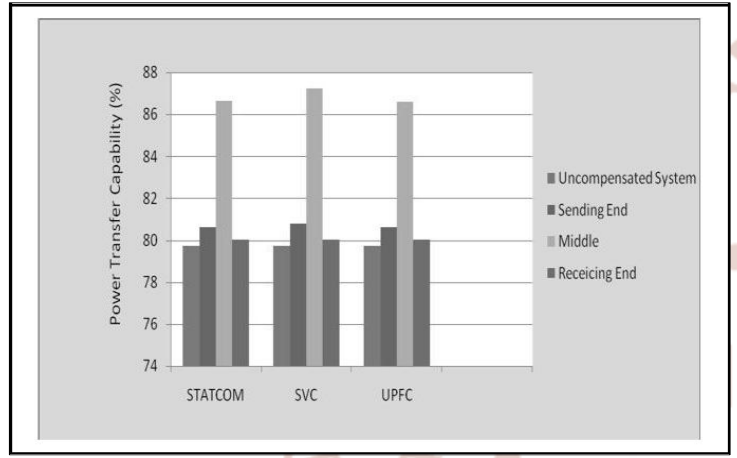

Fig. 23. Comparison of power transfer capability between uncompensated and FACTS compensated system

\section{CONCLUSION}

The power flow and the power transfer capability are the essential attributes which are to be controlled and increased by using the FACTS devices for long transmission line. In this paper FACTS devices such as STATCOM, SVC and UPFC were connected in various locations i.e. sending end, middle and receiving end of the long transmission line. The results have been obtained in both compensated and uncompensated system. By observing all the results it is concluded that if FACTS devices are used in the middle of the long transmission line then the power flow result will be better than uncompensated system. From the above results it is also seen that $87.24 \%$ power has been transferred when SVC is connected at the middle of the transmission line.

\section{ACKNOWLEDGMENT}

My heartiest respect is extended towards my guides and all other faculty members for their valuable guidance, suggestion and inspiration to carry out this work in a proficient manner.

\section{REFERENCES}

1. Ch. Chengaiah, R.V.S. Satyanarayana, "Power flow assesment in transmission lines using simulink model with upfc", 2012 International Conference on Computing, Electronics and Electrical Technologies [ICCEET].

2. M. Karthikeyan, P. Ajay-d-Vimalraj, "Analysis and comparison of power flow and power transfer capability in a long transmision line using shunt facts devices", European Journal of Scientific Research, Vol.73 No.2 (2012), pp. 210-220

3. K. R. Padiyar, "FACTS controllers in power transmission and distribution," New Age Int. Publisher, 2007.

4. Anulekha Saha, Priyanath Das, Ajoy Kumar Chakraborty, "Performance analysis and comparison of various FACTS devices in power system". International Journal of Computer Applications (0975-0887) Volime 46- No.15. May 2012.

5. Dr. B. R. Gupta \& Er. Vandana Singhal, "Power system operation and control", S. Chand Publications.

6. Parvej Khan, Himmat Singh, "Power flow control in a transmission line through upfc", International Journal of Emerging Technology and Advanced Engineering, Volume 2, Issue 12, December 2012.

7. Samima Akter, Anulekha Saha, Prof. Priyanath Das , "Modeling, simulation and comparison of various facts devices in power system", International Journal of Engineering \& Technology (IJERT), Vol. 1 Issue 8, October2012. 